\title{
Ice Thickness Measurements of the Southwest Greenland 2000-m Contour Line
}

\author{
J. J. Legarsky, S.P. Gogineni, P. Kanagaratnam, T. L. Akins and Y. C. Wong \\ The University of Kansas, Radar Systems and Remote Sensing Laboratory \\ 2291 Irving Hill Road, Lawrence, KS 66045, USA \\ 785/864-4835 (T) - 785/864-7789 (F) - graham@rsl.ukans.edu
}

\begin{abstract}
During 1998, the University of Kansas Radar Systems and Remote Sensing Laboratory performed ice thickness measurements along several flights in the southern part of Greenland. We used an improved coherent radar depth sounder operating at $150 \mathrm{MHz}$ to collect these data. We obtained ice thickness data along flight lines for which no reliable thickness information was available. In this paper we present results from these experiments along a $2000-\mathrm{m}$ contour line in the southwestern part of the Greenland.
\end{abstract}

\section{INTRODUCTION}

Since 1993, we have been performing radar ice thickness measurements as a part of NASA's Program for Arctic Regional Climate Assessment (PARCA). The primary goal of PARCA is to determine the mass balance of the Greenland ice sheet. It consists of a coordinated set of spaceborne, airborne and in-situ measurements to address the primary objective. The radar we have been using for ice thickness measurements was originally developed for sounding ice over the Antarctic Ice sheet [1]. It operates at $150 \mathrm{MHz}$ and transmits a 1.6-um long chirped pulse with peak power of about $200 \mathrm{~W}$. The received signal is compressed to a $60-\mathrm{ns}$ long pulse in the receiver and integrated coherently and incoherently to obtain the high sensitivity required to measure 3000-m thick ice.

During 1993, we observed that this system did not have adequate sensitivity to measure ice thickness in some parts of southern Greenland. To improve its performance we redesigned and rebuilt both the analog and digital subsections of the system $[2,3]$ and developed a SAR processing algorithm for ice sounding radar. Also, we redesigned and rebuilt the antenna system, which increased the sensitivity by about $8 \mathrm{~dB}$.

We collected a large volume of data using the improved system in June-July 1998, including the 2000 -m contour line, where high-quality ice thickness data are sparse because the warm ice of SWG attenuates the radar signal more than the colder ice in other regions of Greenland. We applied a focussing algorithm to obtain additional sensitivity needed to obtain ice thickness along the 2000-m contour line.

\section{ANALYSIS}

We processed the 1998 data from the $360-\mathrm{km}$ SWG 2000 $\mathrm{m}$ contour line, where high-quality ice thickness data have been sparse. The ice thicknesses from the SWG line are shown in Figure 1. Ice thickness values vary from about 400 $\mathrm{m}$ to $1650 \mathrm{~m}$ over the SWG line. Figure 2 shows the location of the SWG flight line on a Greenland map. The radio echogram is shown in Figure 3. About the first $300 \mathrm{~m}$ shown below the top are dark due to excessive receiver blanking. The bedrock at elevations above about $1000 \mathrm{~m}$ appears bright and vertically thick due to the logarithmic scaling of the image. We use the WGS84 ellipsoidal height for the $y$-axis label shown on the image. We use the distance along the flight line for the $\mathrm{x}$-axis label shown on the image. The top of the ice sheet is at elevations from about $1800 \mathrm{~m}$ to $2000 \mathrm{~m}$. The ice-bedrock interface starts at an elevation of about 250 $\mathrm{m}$ and ranges from about $250-\mathrm{m}$ to $1400-\mathrm{m}$ elevations. After processing, about $99 \%$ of the ice-bedrock interface is identified. In the regions around $230 \mathrm{~km}$ and $290 \mathrm{~km}$ with valley-like topography the radar signal is weak. To compute the ice thickness in those regions the ice-bedrock interface was interpolated.

\section{CONCLUSION}

We presented ice thickness data for SWG 2000-m contour line. We believe this data set represents the first high-quality extensive ice thickness measurements along the southwest Greenland $2000-\mathrm{m}$ contour line, which will decrease the uncertainty in the output flux computation of the region.

We have successfully acquired radar depth-sounding data every year since 1993, and have published several refereed papers based on our ice-thickness data; furthermore, we refined the radar to the level where we now make field measurements routinely. Since 1993, we have been providing ice-thickness measurements of the Greenland ice sheet to scientists worldwide. There are several papers partly based on the radar ice-thickness data, which have been or soon will be published, such as [4], [5], [6] and [7].

\section{ACKNOWLEDGMENTS}

This research was supported by funds from NASA under grants NAG5-6345 and NGT5-30029. 


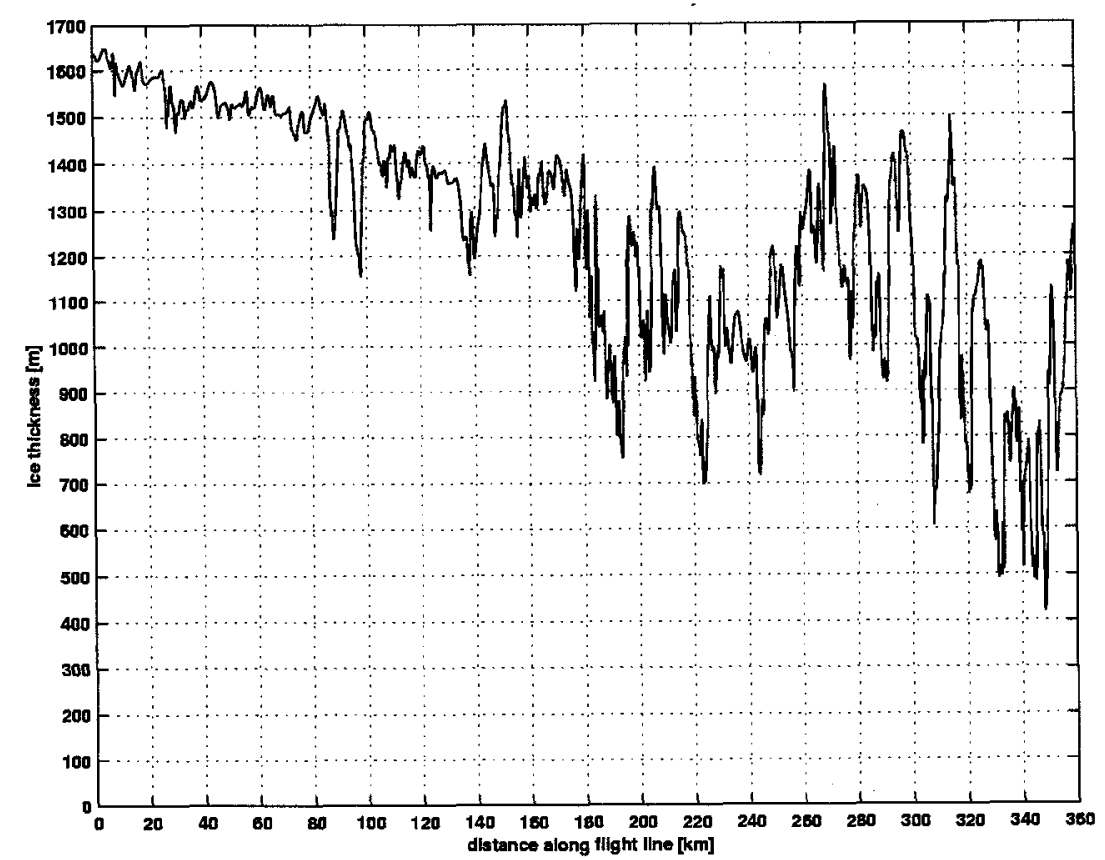

Figure 1. Ice thickness data measured along the 360-km SWG 2000-m contour line flown in 1998.

\section{REFERENCES}

[1] G. Raju, W. Xin, and R. K. Moore, "Design, development, field operations and preliminary results of the coherent Antarctic radar depth sounder (CARDS) of the University of Kansas, USA," J. Glaciology, vol. 36, 123, 247-258, 1990.

[2] T. S. Chuah, Design and Development of a Coherent Radar Depth Sounder for Measurement of Greenland Ice Sheet Thickness, Ph.D. Dissertation, University of Kansas, January 1997.

[3] T. L. Akins, Design and Development of an Improved Data Acquisition System for the Coherent Radar Depth Sounder, M.S. Thesis, Univ. of Kansas, December 1998.

[4] J.Legarsky, A.Wong, T.Akins,\&S.P.Gogineni, "Detection of hills from radar data in central-northern Greenland," Journal of Glaciology, vol.44,no.146, 1998, pp. 182-184.

[5] E. J. Rignot, S. P. Gogineni, W. B. Krabill, and S. Ekholm, "North and northeast Greenland ice discharge from satellite radar interferometry," Science, vol. 276, pp. 934-937, 9 May 1997.

[6] C. Allen, S. Gogineni, B. Wohletz, K. Jezek and T. Chuah, "Airborne radio echo sounding of outlet glaciers in Greenland," International J. Remote Sensing Letters, vol. 18, no. 14, pp. 3103-3107, 1997.

[7] D. Dahl-Jensen, N. S. Gundestrup, K. Keller, S. J. Johnsen, S. P.Gogineni, C. T. Allen, T.S. Chuah, H. Miller, and S. Kipfstuhl, "A search in north Greenland for a new ice core drill site," Journal of Glaciology, vol. 43, no. 144, June, 1997, pp. 300-306.

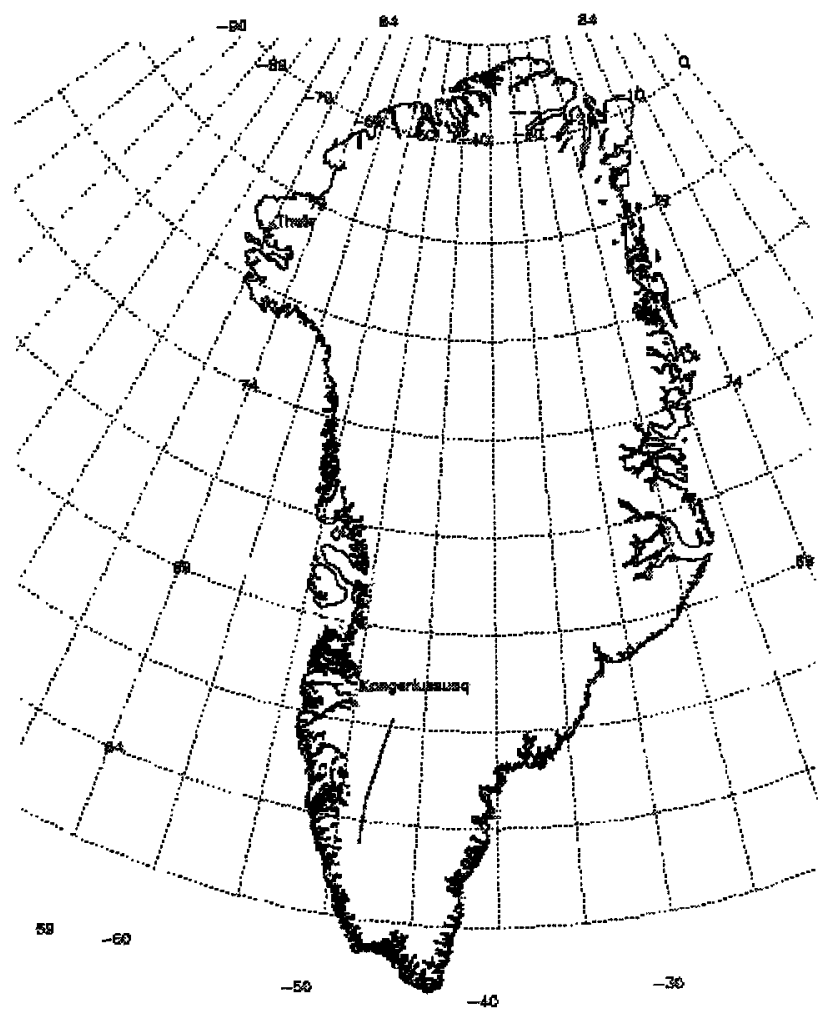

Figure 2. Map of Greenland showing the location of the SWG flight line. 

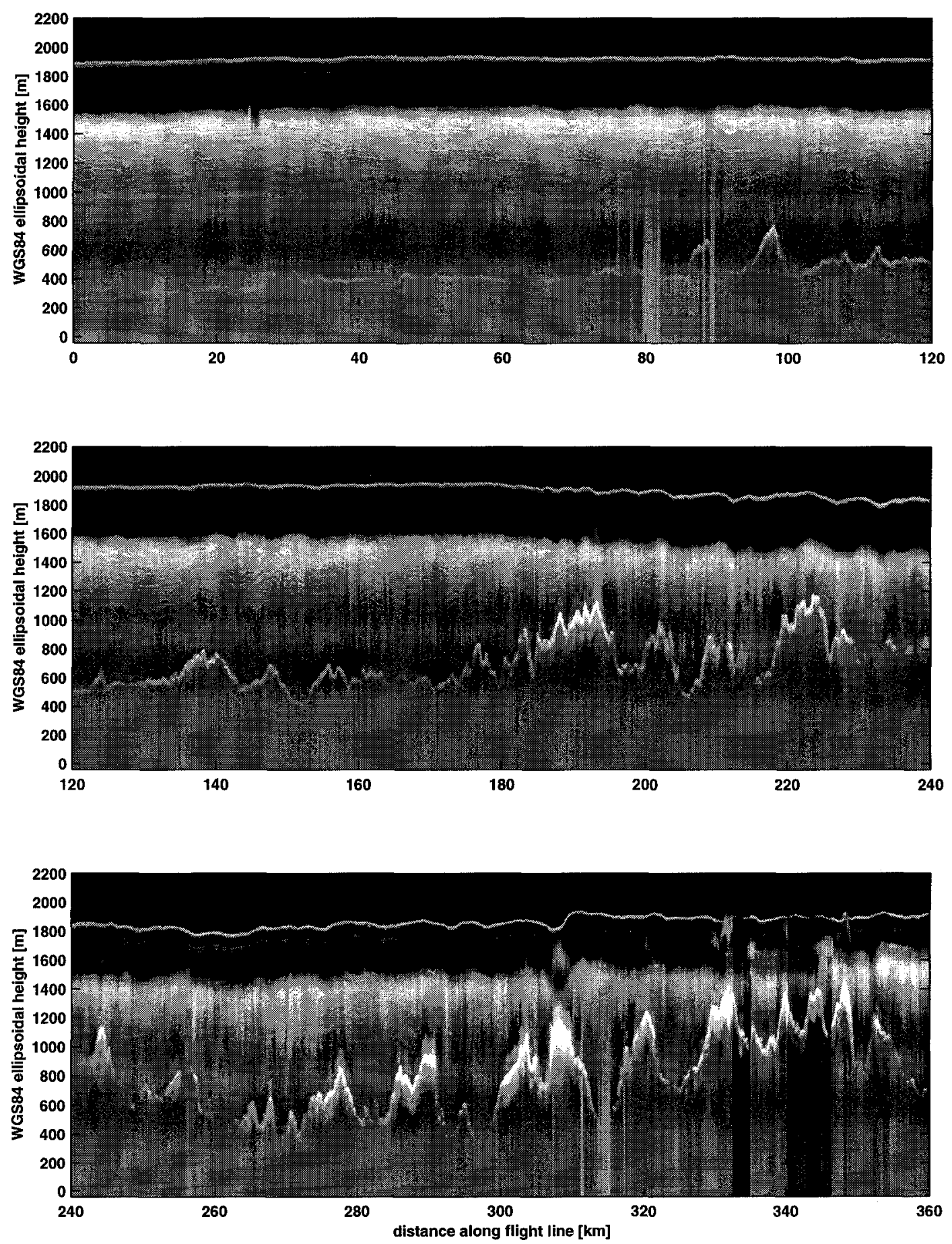

Figure 3. Radio echogram from the 360-km SWG 2000-m contour line flown in 1998, where highquality ice thickness data has been sparse. About the first $300 \mathrm{~m}$ shown below the top are dark due to excessive receiver blanking. The top of the ice sheet is at elevations from about $1800 \mathrm{~m}$ to $2000 \mathrm{~m}$. The ice-bedrock interface starts at an elevation of about $250 \mathrm{~m}$ and ranges from about $250-\mathrm{m}$ to 1400 m elevations. 